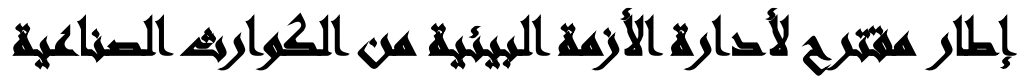

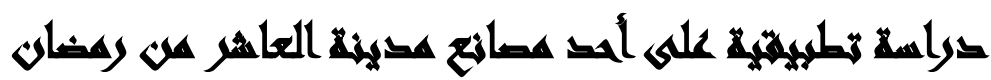

\section{[1 \{]}

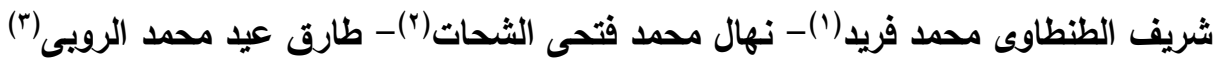

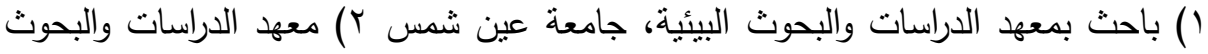

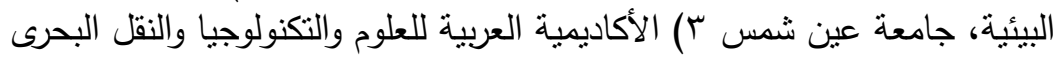

\section{همترلصن}

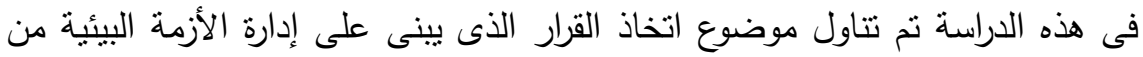

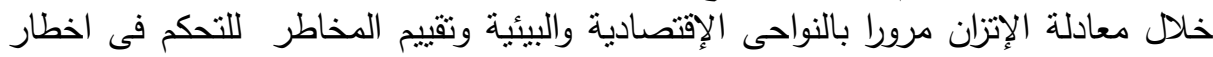

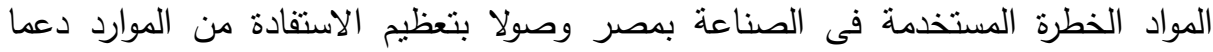

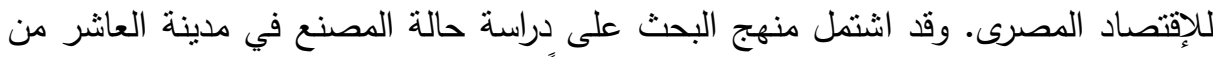

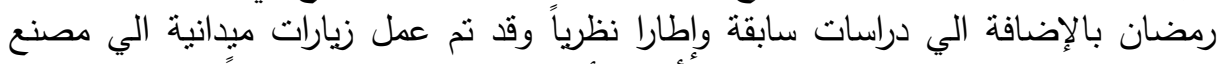

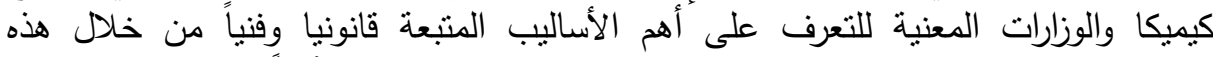

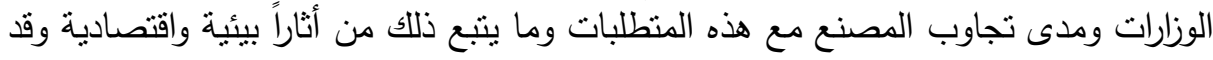

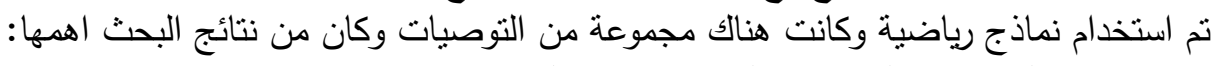

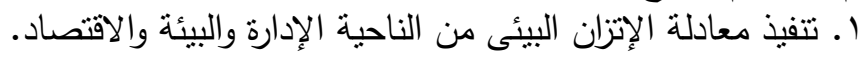

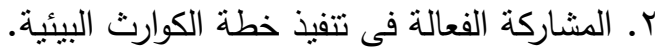

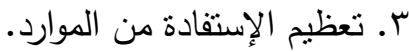

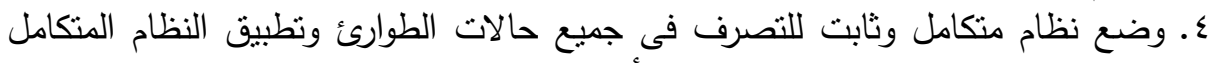

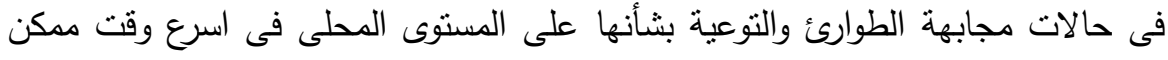
بمعنى عمل الترتيبات وتوفير التمويل اللازم للمحافظة الدائمة على نظام التوعية والمجابهة

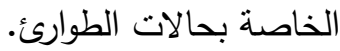
ه. تطوير المنظور الوطنى للمخاطر للمنشآت الخطرة فى مصر . 


\section{xasadl}

إن الأحداث الحالية أظهرت الأهمية القصوى لقضية الأمن والاستعداد لحالات الطوارئ

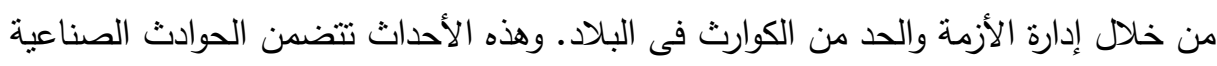
التى تتسبب فى الخسائر الكبيرة للبيئة وفى الأرواح والممنلكات وما يتبعه من إهدار للموارد.

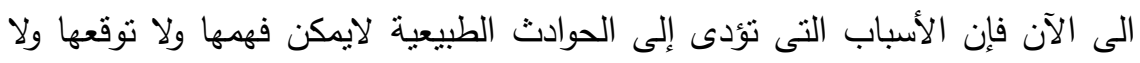

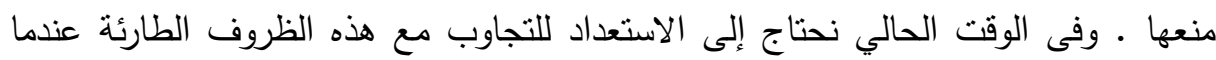

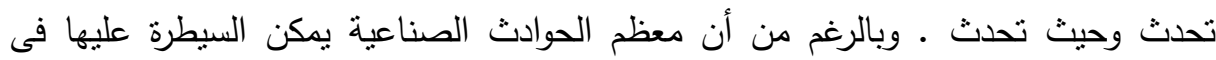
حدود المنشأة الصناعية إلا أن هناك بعض الحالات بمن الحند الخطر فيها إلى خارج المنشأة لتؤثز على الزراعات والمممتلكات المجاورة فيكون لها أخطار شديدة نؤئز على الحياة والمثنكات والاقتصاد وعلى المجتمع كله. وكم الخسارة الذى تسببه هذه الحوادث يعتمد إلى درجه كبيرة

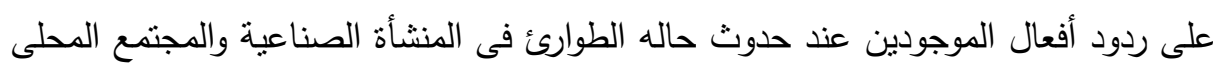

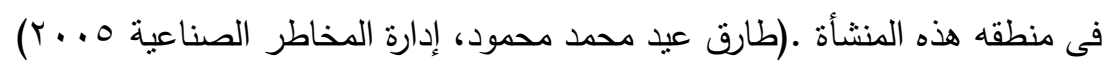

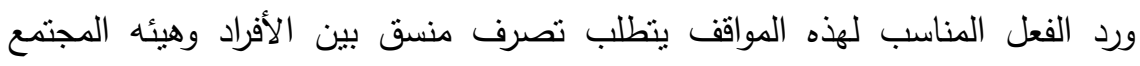

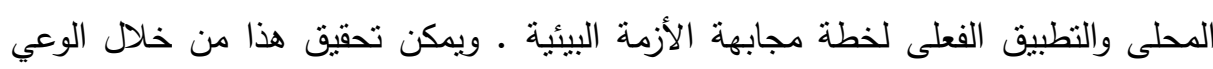

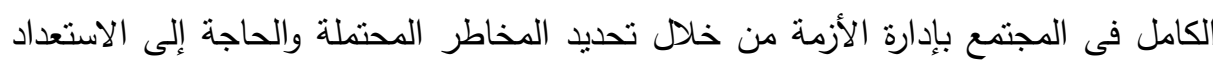

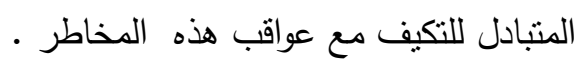
الهدف الرئيسي للرسالة هو زيادة توعيه الجميع فى المجتمع بالآزمات التى قد تتواجد

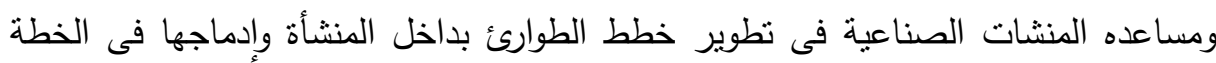
الوطنية لإدارة الأزمات والكوارث. • تعتبر عملية اختيار ووصف وتحديد المنطقة النى قد نسبب أزمه من أهم النقاط في نظام

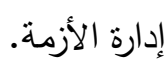
• الأسس الملائمة لاختيار منطقة الدراسة تعتىد بشكل مستقل طبقاً لكل حالة على حده. منطقة الدراسة هي المنطقة الصناعية التي تؤثر بشكل مباشر على الصحة العامة والبيئة في حالة وقوع أزمة بها. ولا يمكن وضع أسس جامدة لهذا الاختيار ولا يمكن إعطاء 
معايير ملزمة في هذا الخصوص ، يمكن الاستفادة من الخبرات السابقة في هذا المجال بالإضافة إلى نتائج النماذج الرياضية للمساعدة في تحديد هذه المناطق. يمكن الوضع في الاعتبار هذه البنود:

1. اختيار منطقة الدراسة يعتمد على خصائصها الطبيعية، الاقتصادية، الصناعية، ويمكن

$$
\text { الوضع في الاعتبار الحدود الجغرافية والإدارية لها. }
$$

r. لا يمكن وضع حدود صارمة لهذه المناطق قبل التقييم الأولي لإدارة الأزمة لهذه المنطقة والذي قد يكون مؤثر ولم يوضع في الاعنبار من قبل. r. نظام نقل وتحميل وتقييم المواد الخطرة بهذه المنطقة.

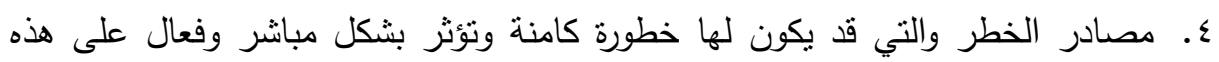

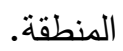

• في بعض الحالات، ممكن وقد يكون ملائماً الوضع في الاعتبار إجراءات إدارة الأزمه من

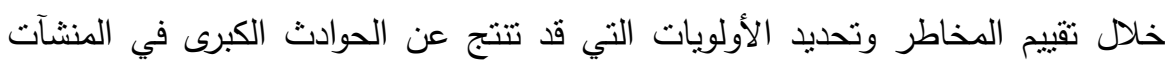
الموجودة ذات العلاقة.

• الخطوات التي استخدمت في هذه الرسالة طبقت على الحوادث العظمى التي لها تأثنير

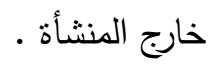
• الخطورة الكامنة التي تمت دراستها هي: الحريق، الانفجار، تحديد الغازات السامة والقابلة للاشتعال وتأثثراتها على الصحة العامة والبيئة. • أول خطوة في عملية تحليل المخاطر هي تعريف وتحديد مصادر المخاطر وخصائصها

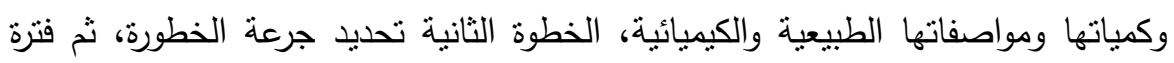
التعرض ثم بعد ذلك عمل تقييم المخاطر والكمية وتحديد المنشآت ذات الخطر الجسيم كما وماله هو مبين فى الثكل رقم ا وعمل المنظور الوطنى للمخاطر كما هو مبين فى الثكل r. (van den B erg, 1985, . A framework for vapour c loud explosion blast prediction) 
• هنالك عدة نقاط يجب أن تؤخذ في الاعتبار وهي وجود عدم دقة متتاهية للبيانات التي قد تتتج من عمليات تقييم المخاطر ولكنها تعطي خطوط إرشادية للعمل بها للحد من هذه وهي

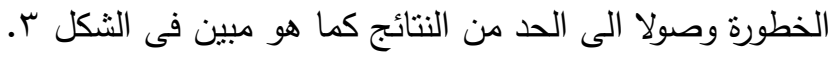
شكل رقم (1): مصفوفة تحديد المخاطر

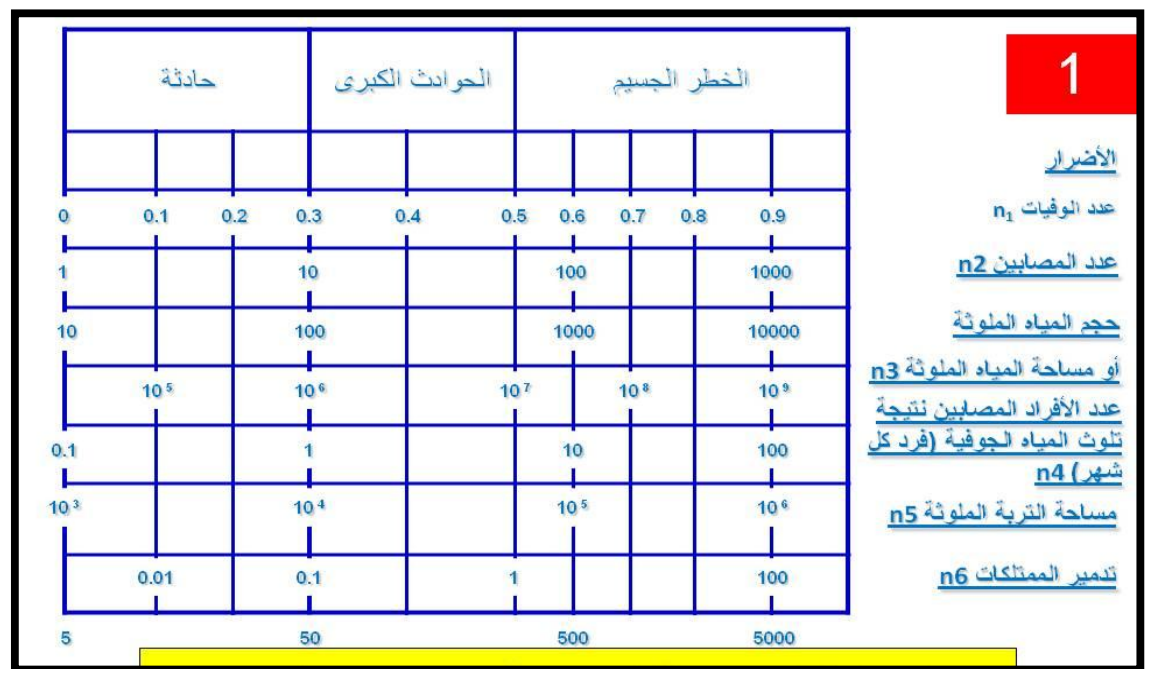

المصدر: برنامج الأمم المتحدة للصناعة والبيئة، برنامج أبل للوعي والاستعداد للطوارئ على المستوي

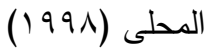

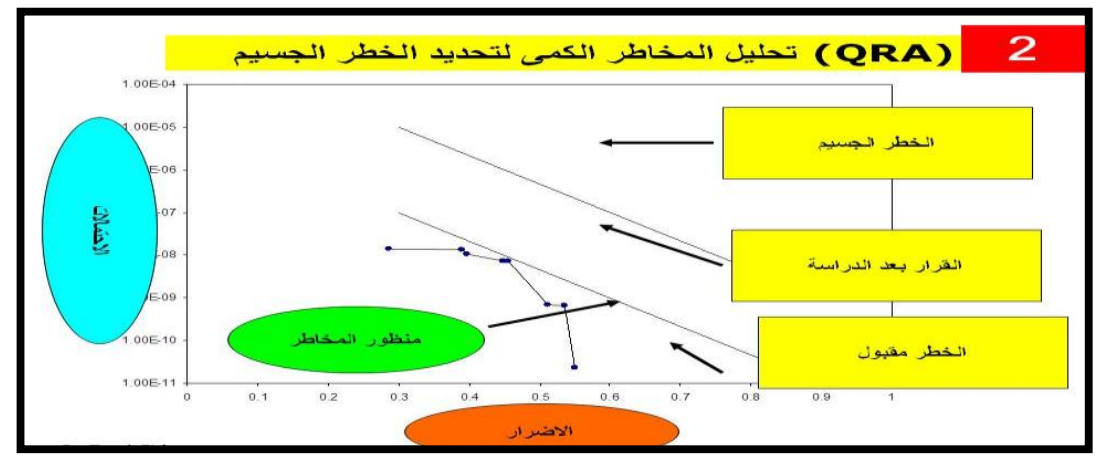

شكل رقم(r): عمل المنظور للمخاطر المصدر: برنامج الأمم المتحدة للصناعة والبيئة، برنامج أبل للوعي والاستعداد للطوارئ على المستوي

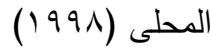




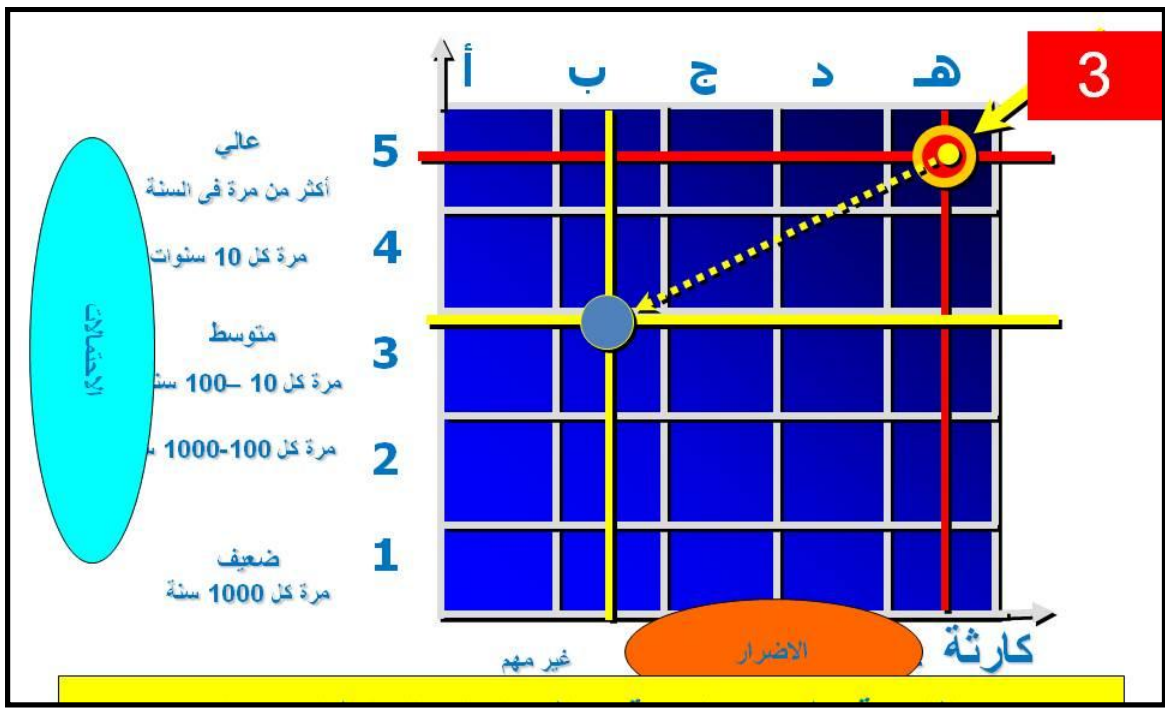

شكل رقم (ץ): المخاطر الكمية والنوعية

المصدر: برنامج الأمم المتحدة للصناعة والبيئة، برنامج أبل للوعي والاستعداد للطوارئ على المسنوي

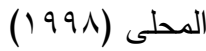

تقييم الخطر البيئي: إن تحليل كميه الخطر هو أداه جيدة لفهم كيفيه التعامل مع عمليات صناعة المواد الكيماوية ـ ويعتبر تحليل كميه الخطر مفيداً جداً عند استخدامه لتقييم الخطر الناتج عن تصنيع منتج ما مقارنه بتصنيع بدائله وكنلك عند استخدامه لتحديد الأسباب

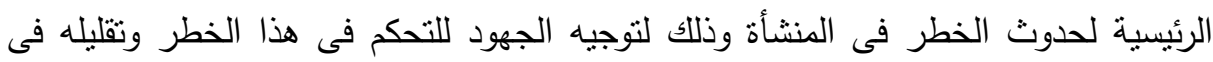
هذه المنطقة حيث يكون لهذا الخطر أثند التأثير ـ ومع ذلك من المؤكد أن استخدام أداة ما التقييم كم الخطر يودى إلى بعض الاستفسارات مثل نلأك المتعلقة باحتمالية حدوث هذا الخطر

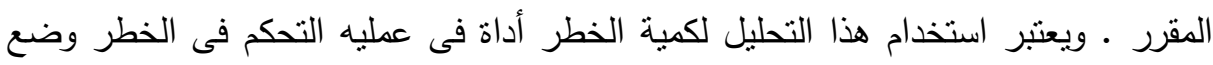
(Bilo M and Kinsman, 1997, risk assessment methodology). القرار 


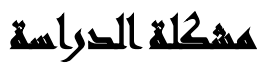

الزيادة السريعة فى استخدام الكيماويات فى الصناعة والتجارة تمثل حوالى تلث الموارد

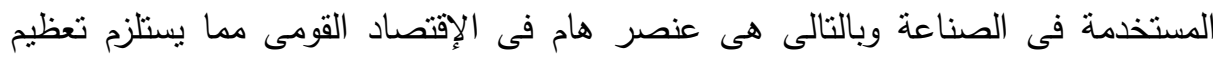

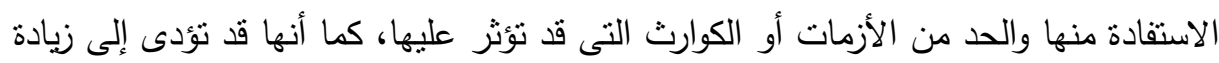
ملحوظة فى زيادة أعداد من تتعرض حياتهم للخطر فى وقت ما سواء الاء أكان هوئلاء من العمال

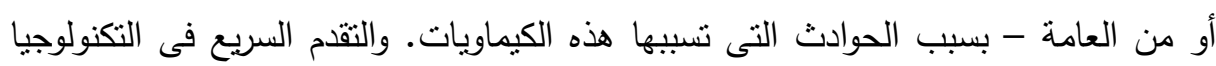

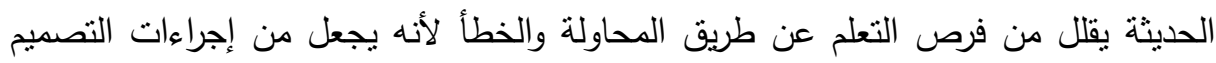

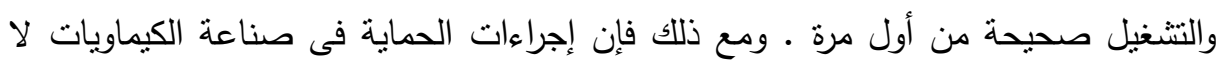

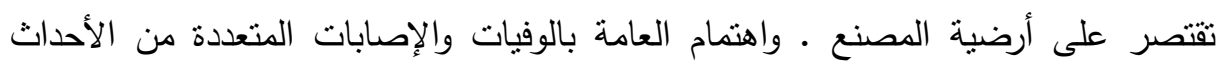

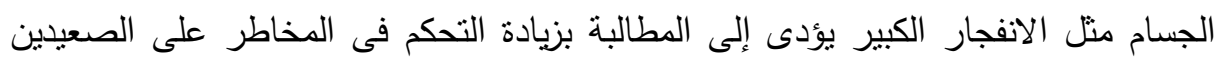

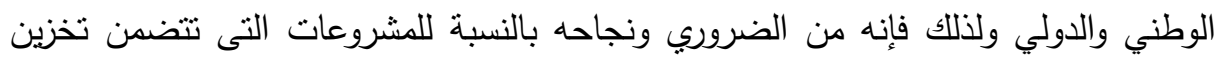

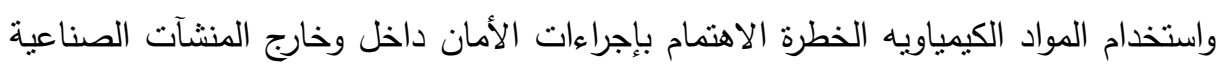

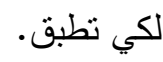

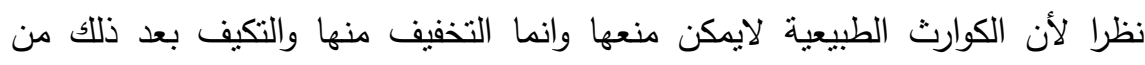

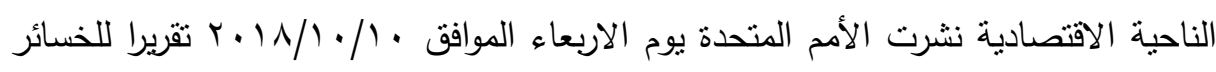

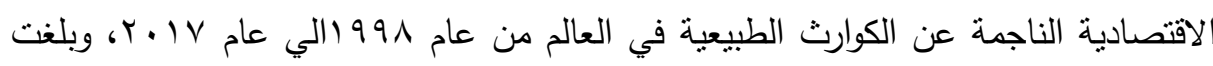

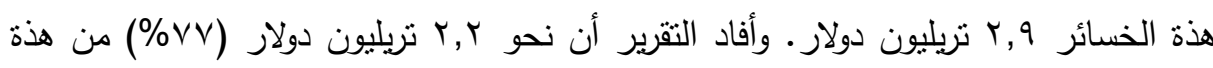

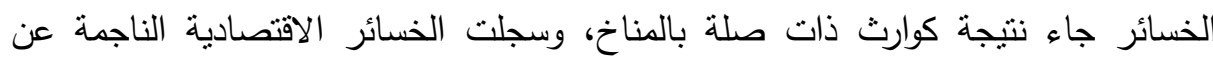

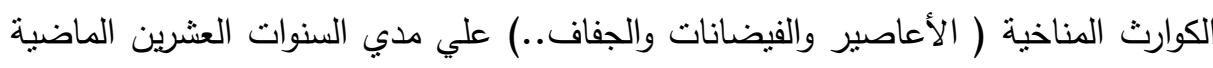

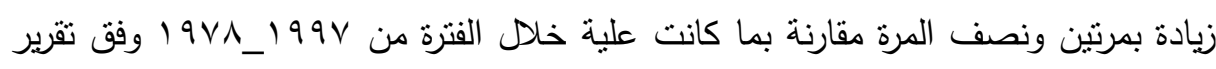

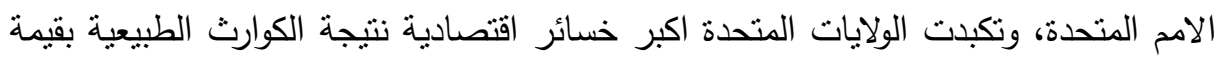

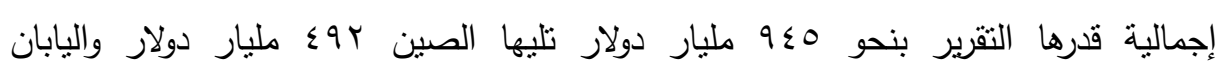

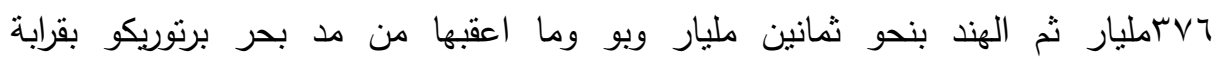

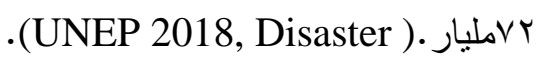


خلال العقدين لقي نحو r, (مليون شخص حتفهم واصيب ؟ ــملاين شخص وتسبب

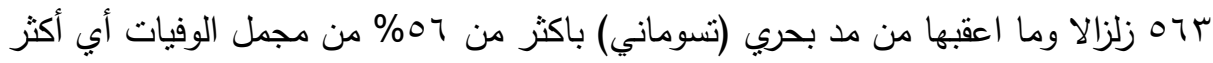

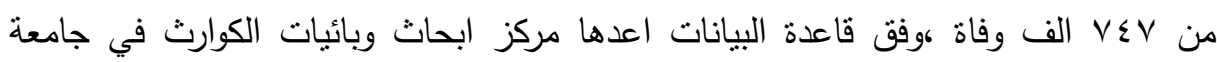

لوفان الكاثولكية ببلجيكا. (UNEP 2018, Disaster)

حذر علماء متخصصون في الاحوال المناخية من أنه في حال ارتفاع درجة حرارة الارض اكثر من ه,ادرجة مئوية عما كانت علية قبل الحقبة الصناعية فان ذلك سيعرقل

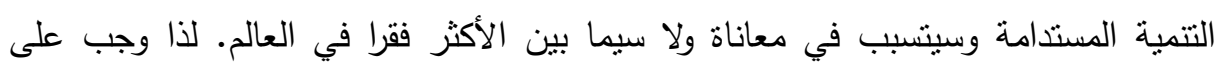

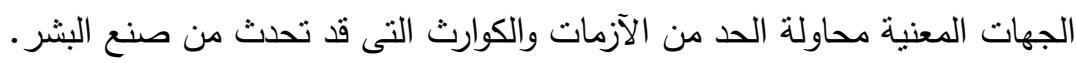
والمشكلات الرئيسية يمكن إيجازها كما يالي: ا ـ عدم وجود القدرات التى يمكن عن طريقها تقييم درجة الخطورة والسمية المحتملة والتحكم

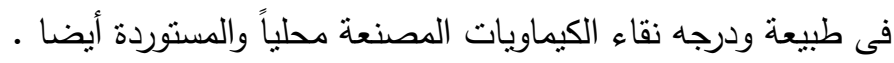
r. استخدام العمال قليلو الكفاءة والمعرفة بألمواد الكيماوية الخطرة. r. نقص مهارات الإدارة المطلوبة للتعامل الآمن مع تكنولوجيا النقل ومع تخزين ونقل والتخلص من الكيماويات الخطرة. ع. قله وسائل التعامل مع الحوادث الناتجة عن استخدام الكيماويات الخطرة والتى تثمل علاج المصابين والأحداث اللاحقة.

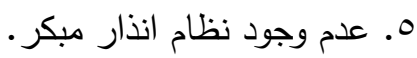

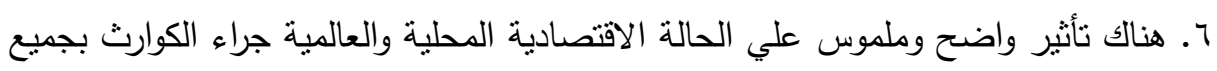

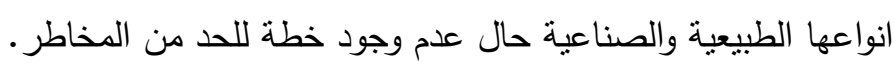

\section{هغوضر التواسمة}

- توجد علاقة جوهرية بين الآثار البيئية ورأس المال الاستثماري. - توجد علاقة جوهرية بين دور الدولة في دعم الاقتصاد والحفاظ على رأس المال من خلال انقاذ القوانين والقرارات الوزارية.

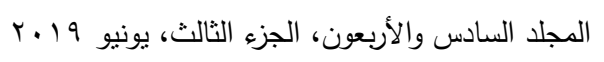


- توجد علاقة جوهرية بين الحفاظ على رأس المال المستثر والوعي لدى العاملين بطاقة القطاعات.

- توجد علاقة جوهرية بين السياسات البيئية والحد من الكوارث والحفاظ على القيمة التتافسية في الصناعات المصرية.

\section{أهمية التوراسة}

$$
\text { - دعم الإقتصاد وتحسين مستوى المعيشة }
$$

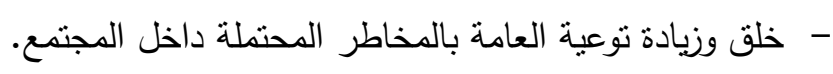
- الحث على تطوير استراتيجية وطنية للتعامل مع حالات الطوارئ المحتملة. - مساندة و المساعدة على منع الحوادث. - جميع النقاط المذكورة عاليه لها تأثير مباشر على على حمانية البيئة والاقتصاد.

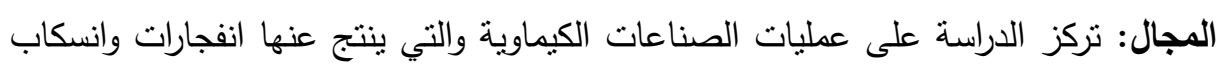
وانبعاثات للمواد الكيماوية الخطرة. ويمكن بقليل من الحكمة تحديد العناصر التى قد تمثل سبيا

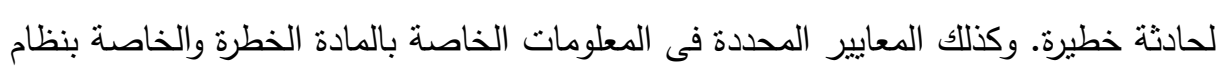

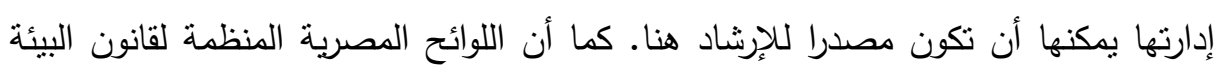

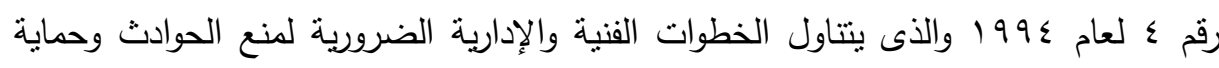
العامة والعمال وحماية الصحة والبيئة هذه اللوائح نساند البحث وتدامعه.

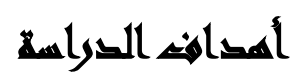

حماية البيئة والصحة العامة وذلك بتطوير نظام للإدارة يساعد صناع القرار وهئية

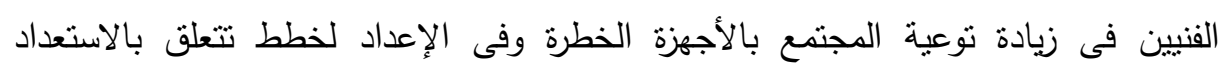

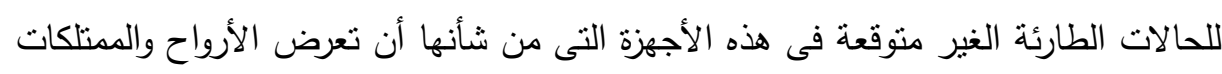
والبيئة للخطر . 
أ- حماية المجتمع من الخسائر فى الأرواح والممتلكات والبيئة عن طريق: ا. توعية المجتمع والمسئولين عن التصرف فى فلى حالات الطوارئ بالمخاطر الموجودة فى في

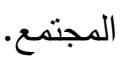
r. تطوير خطط طوارئ متكاملة يمكن من خلالها التعامل بفعالية مع الحوادث التى قد تتطور

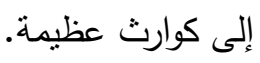
r. تدريب سكان هذا المجتمع على كيفية التصرف فى حالات الطوارئ.

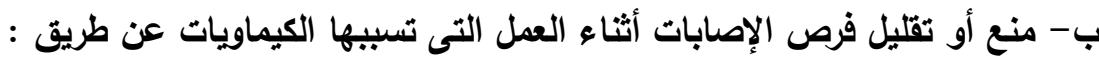

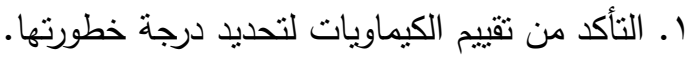
r. إعلام المديرين بطريقة تمكنهم من الحصول على معلومات دربات عن المواد الكيماوية المستخدمة فى العمل من القائمين على إمدادهم بالكيماويات حتى بمكنهم تتفيذ برامج فعالة العالة لعماية العمال من المخاطر الكيماوية. r. إدداد العمال بالمعلومات الخاصة بالكيماويات الموجودة فى أماكن عملهم وعن الإجراءات المناسبة الخاصة بحمايتهم حتى يمكنهم المشاركة بفعالية فى برامج الحماية.

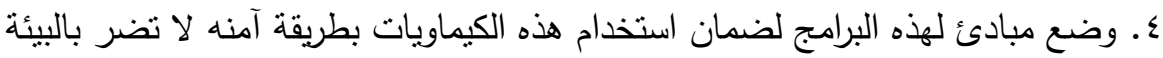
ج. التأكد من اتخاذ الإجراءات المناسبة من أجل: ا ا. منع أو الحد من وقوع الأزمة البيئية. r. r. تقليل حجم المخاطر الناتجة عن الحوادث الكبة الكبيرة. r. تقليل آثار الحوادث الكبيرة علي الصحة والييئة والإقتصاد.

\section{المنهمير}

تطبق المنهجية علي إدارة الأزمة البيئية وتقييم حجم الخطر البيئى والإقتصادى من خلال: أ) أ دراسة مكتبية.

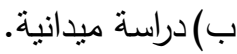




\section{إباراً يطلاياً}

هذه الدراسة تغطي منهجية إدارة الأزمة البيئية وصولا الى تقييم حجم الخطر وإدارة

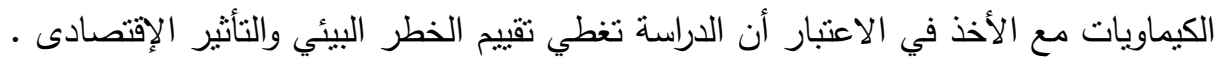

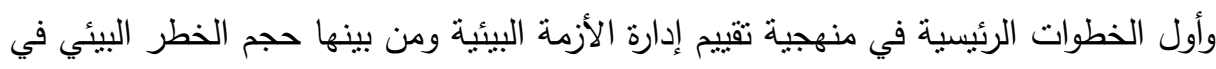
منطقة ما هو رسم صورة لمنطقة مناسبة للاراسة. والقواعد التي ينم علي أساسها الاختيار تعتمد علي الظروف الخاصة بكل حالة. والمنطقة موضع الدراسة تعرف علي أنها المنطقة

التي قد تتعرض فيها صحة الإنسان والبيئة للخطر بسبب المنطقة الصناعلة الصنية المجاورة لها.

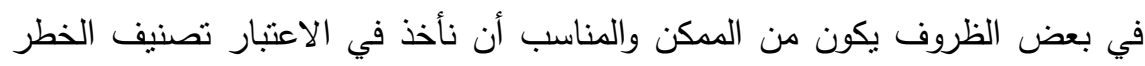

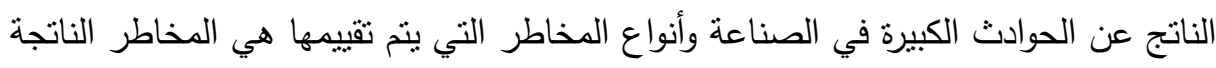

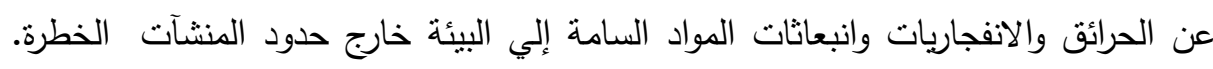
وذلك يشمل أيضا الخطر علي صحة العمال والخطر المتعلق بالبيئة الطبيعية.

\section{الإجراعائ المنهجية}

دراسة ميدانية: تم اختيار منطقة العانر من رمضان الصناعية / الشركة العامة للكيماويات

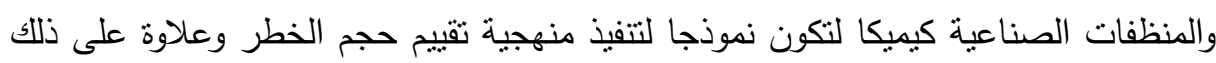
فإن المناطق السكنية حول هذه المنطقة الصناعية معرضة لنلوث الهواء نتيجة للانبعاثات

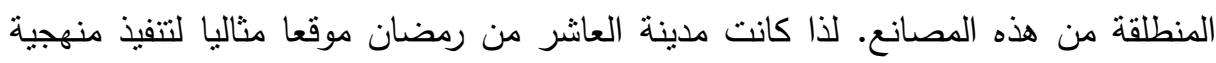

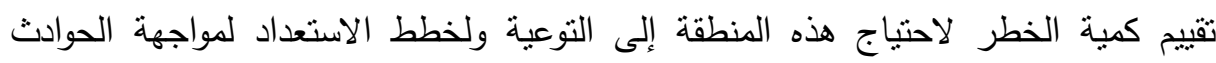
الكيماوية والتى قد تتتج عن هذه المصانع. ومن الواضح أن تتفيذ منهجية تقييم كمية الخطر

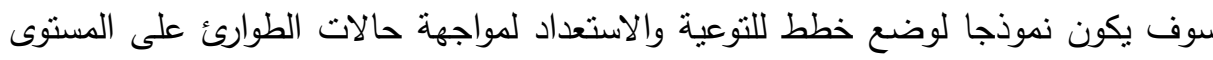
المحلى. 1. وصف مختصر لدراسة المخاطر 


\section{التقرير الخاص بتقييم المخاطر لابد أن يحتوى على:}

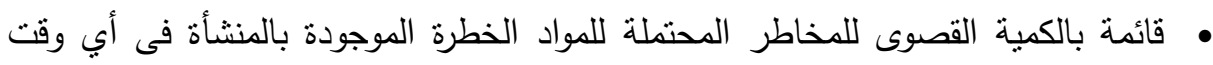

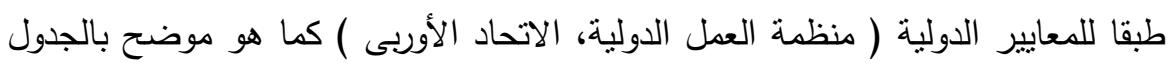

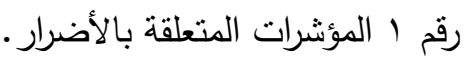

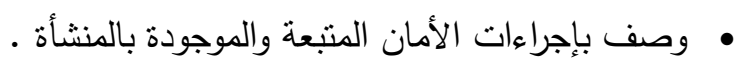
• • دراسة تقديرية بألا ضرار المتوقعة على الصحة العامة والبيئة فى حالة وقوع حادثة. جدول رقم(1) : يحدد المؤشرات المتعلقة بالأضرار

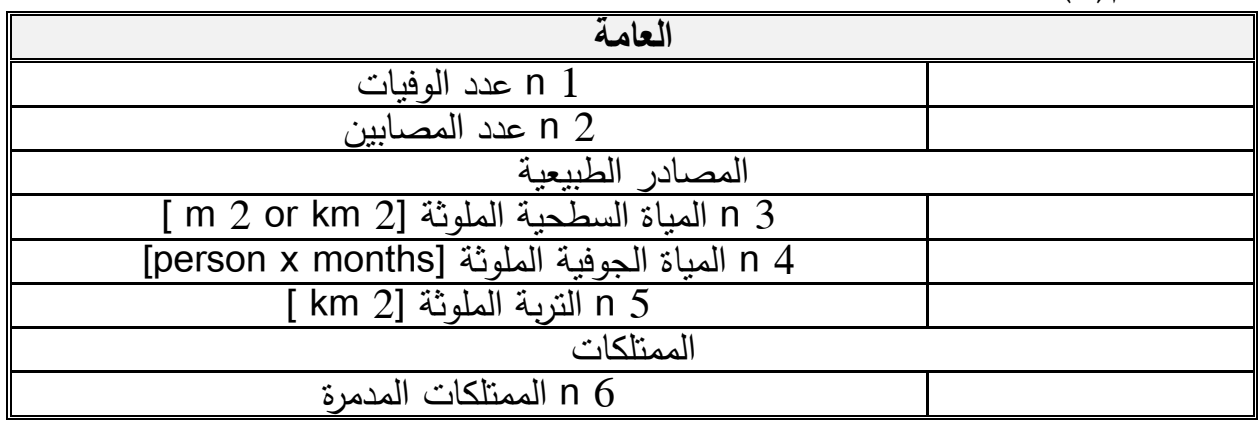

تقييم سيناريو الحدث: يتم تقييم سيناريو الحدث فى الخطوات التالية:

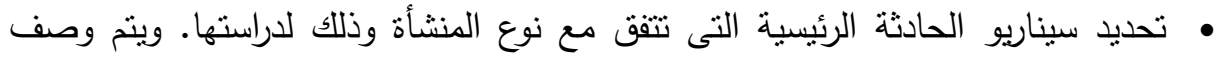
سنياريو الحادثة الرئيسية كظاهرة تمنل رابطة بالتقييم الناتج كما هو موضح فى الجدول

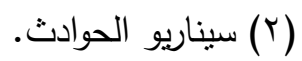

• وصف لتتابع الأحداث المصاحب لسيناريو الحادثة الرئيسية. والمقصود هنا هو الأحداث

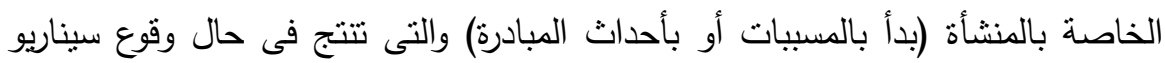

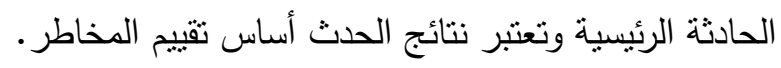
• وضع نماذج لنتائج الحدث فى صورة "شجرة الأخطاء" و "شجرة الأحداث " وللحد من درجة نعقيد نموذج "ثجرة الأحداث" (أعداد لثجرة الأحداث وأعداد لثجرة نتائج الأحداث) يتم تحديد الأحداث المهنية فى بعض الأحيان ويتم حساب عملية تكرار كل حدث مهنى

$$
\text { عن طريق "شجرة الأخطاء" }
$$


ويمكن تحديد كل نتيجة عن طريق منهاج تتازلى بالبحث عن جميع الطرق المؤدية إلى

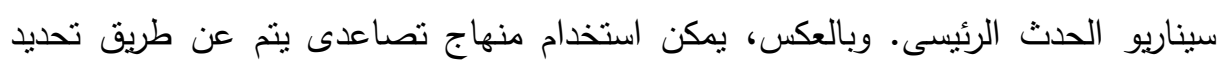

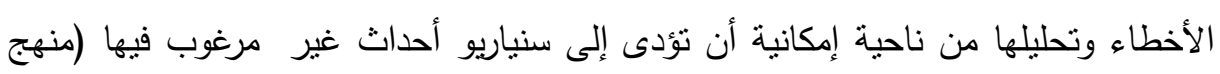
HAZOP

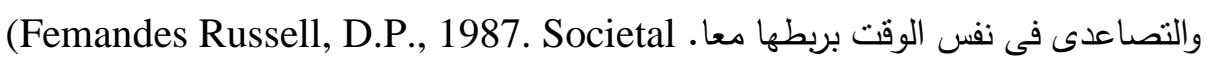

Risk Estimates from Historical Data for UK and Worldwide Events) جدول رقم(r): سيناريو الحوادث

\begin{tabular}{|c|c|}
\hline \multicolumn{2}{|c|}{ الكلور } \\
\hline عناصر الانبعاث (آحداث مهنية) & السنياريو الرئيسي \\
\hline تشربات هائلة (كارثة) & انبعاثات هائلة (كارثة) \\
\hline تسربات هائلة (كارثة) تسرب مستمر & انبعاثات هائلة مستمرة \\
\hline لم يتم تحديدها & انبعاثات بسبطة مستمرة \\
\hline تسرب مستمر & \\
\hline
\end{tabular}

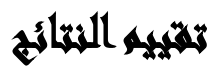

إن المناهج والنماذج المستخدمة لتقييم النتائج تعتمد على العمليات الطبيعية ذات العلاقة

وعلى سيناريوهات نتائج الحدث، وعامة ينم تقييم البنود التالى ذكرها بالنسبة لكل سيناريو : • • كمية المواد الخطرة المستخدمة. • الكثافة أو التركيز فى منطقة التعرض مع الأخذ فى الاعنبار تأثير طبيعة التضاريس وطبيعة بنائها.

$$
\text { • التعرض (منل عدد الأفراد المعرضون ووقت التعرض). }
$$

الكلور، كارثة إنبعاثات هائلة (انفجار الحاوية): يتم حساب كمية غاز الكلور المنبعث من

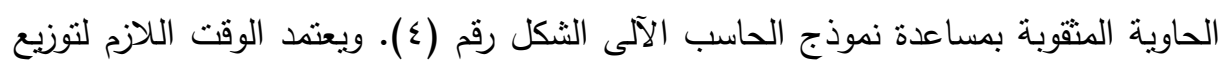
تركيز الكلور على صلابة سطح الأرض وسرعة واتجاه الرياح وقت وقوع الحادثة. وتنتخدم

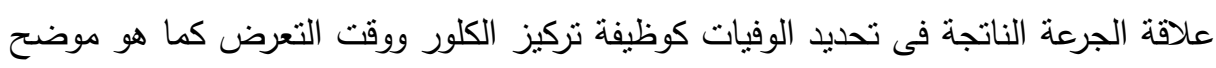

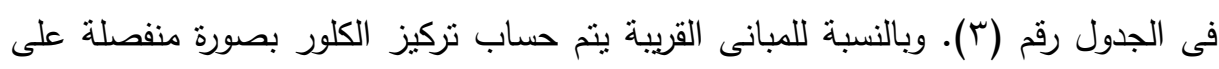

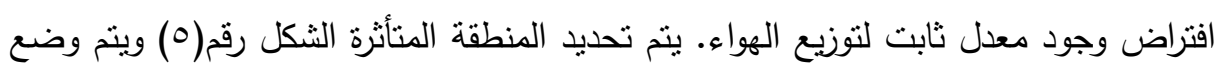
360

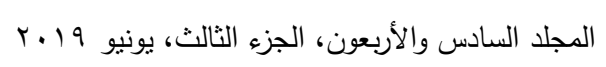


عملية الإخلاء فى الاعتبار عند تقييم فترات التعرض فى السنياريوهات التى يكون زمن

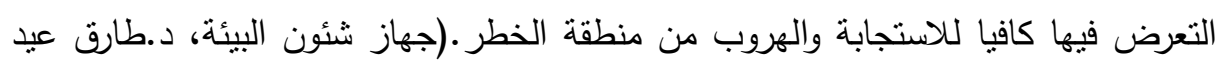

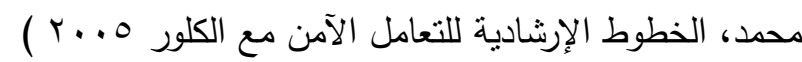

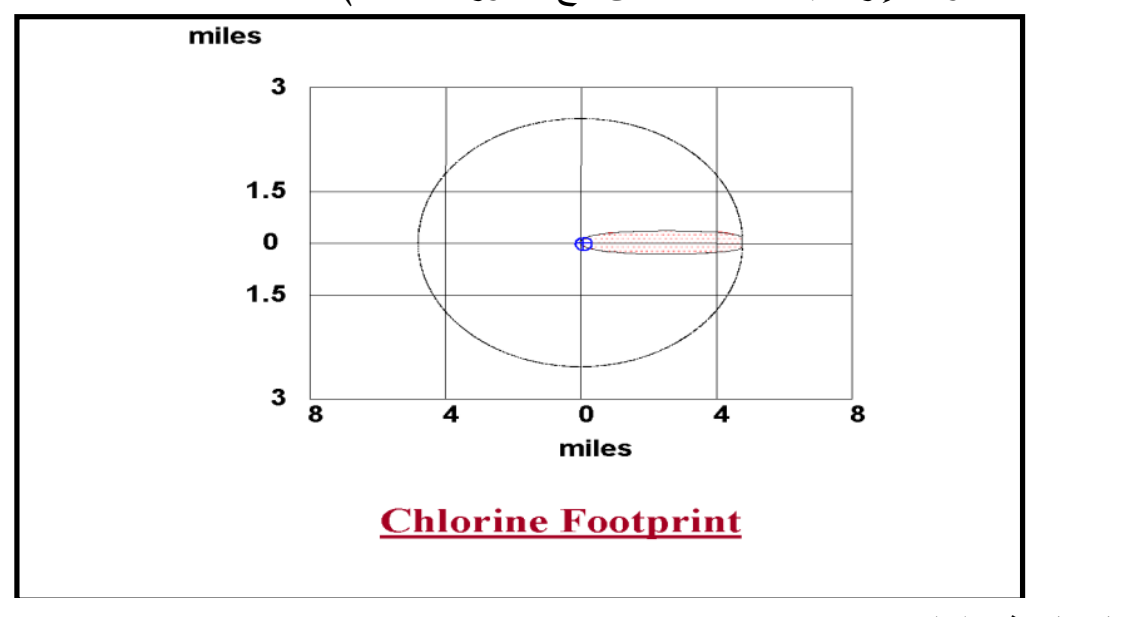

الشكل رقم (ع)

المصدر : برنامج حساب الانبعاثات للغازات المضغوطة (Breeze)

جدول رقم(؟): تأثثرات التركيزات المختلفة لغاز الكلور على الأفراد (تركيز جزء فى المليون

\begin{tabular}{|c|c|c|}
\hline التأثير & الزمن & التركيز \\
\hline 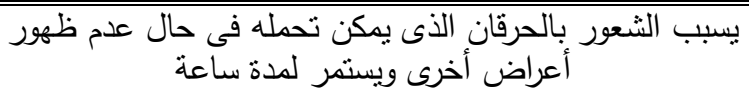 & - & $3-6$ \\
\hline كحه & دقيقة واحدة & 10 \\
\hline تهيج مباشر خطير في الأنف والحلق والعين & 30 30دقيقة & $10-20$ \\
\hline يسبب موث الأشخاص الضعفاء & 10-5 10 & $100-150$ \\
\hline تركيز متوسط قاتل بالنسبة للأشخاص الأصحاء & 30 30قيقة & $300-400$ \\
\hline شديد الخطورة والفتلك & ضيق فى التنفس & 1000 \\
\hline
\end{tabular}




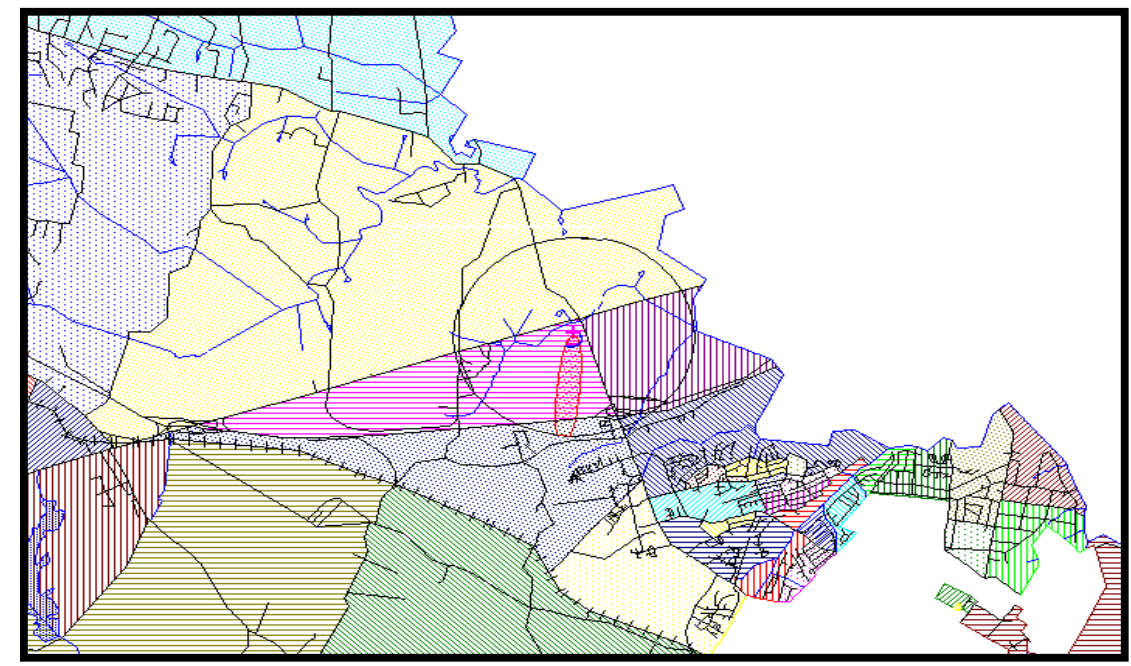

شكل رقم(؟): توضيح للسعة الاسطوانية لانبعاث الكلور (·r طن). نقطة النهاية 9, ؟ ميل.

المصدر: برنامج حساب الانبعاثات للغازات المضغوطة (Breeze)

التقدير ومقارنة المخاطر: إن إمكانية إحداث التأثثر يعبر عنها كميا بالنظر إلى إلى تكرار سنياريو الحادثة. وينقسم الرسم التوضيحى بالثكل (0) إلى أربعة مناطق (مجالات):

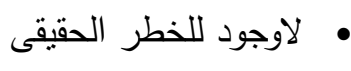

$$
\text { • • }
$$

فى تقدير المخاطر ومقارنتها يتم قياس التكرار السنوى للسنياريو ذا العلاقة بقيمة الكارثة

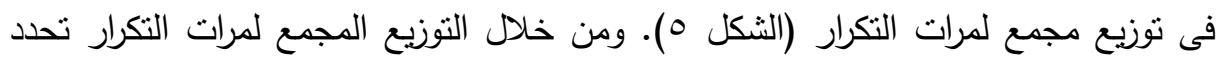
طبيعة الخطر من حيث كونها مقبولة أو غير مقبولة.

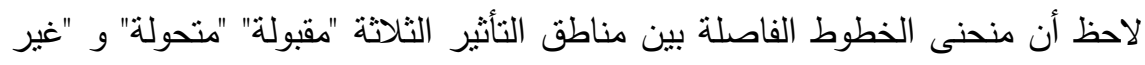

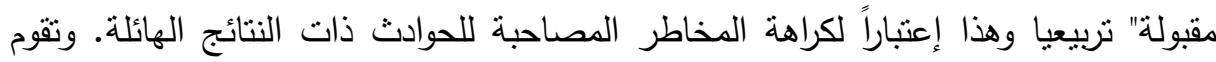
السلطات الملزمة بتقييم حجم المخاطر كالتالى: 
• إذا دخل منحنى التكرار المنطقة "غير المقبولة" يلتزم ماللك المنشأة بالحد من تلك المخاطر

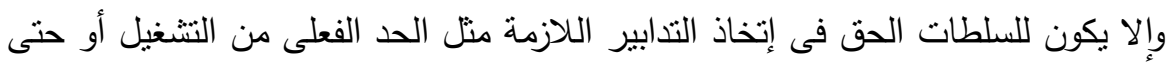
اغلاق المكان.

• إذا دخل منحنى التكرار المنطقة "الانتقالية" تقوم السلطات الملزمة بقياس مصلحة مالك المنشأة بالمقارنة بالمنطلبات الخاصة بالعامة والبيئة بما يحقق الحماية من أخطار

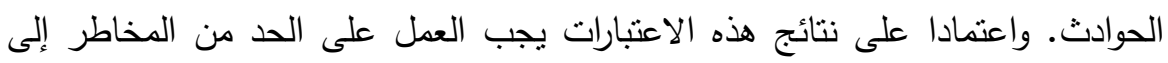
المعدل الذى تراه السلطات مناسبا.

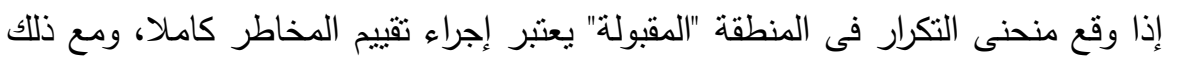

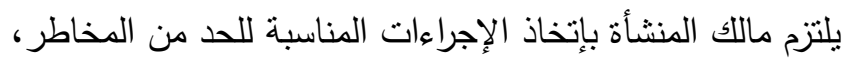
للحصول على معرفة اكثر بمسببات المخاطر الرئيسية يمكن رسم منحنيات منفصلة

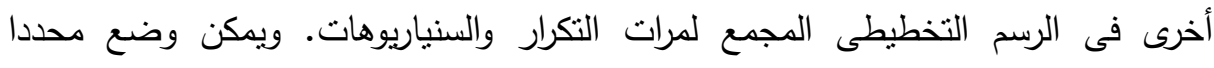

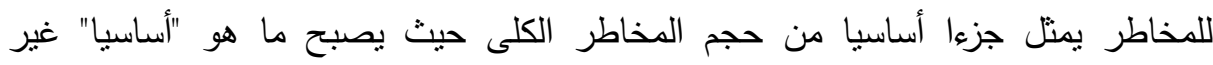
موضحا بما يكفى. وتعتبر قابلية التعرض للخطر من محددات المخاطر التى يكون سببها

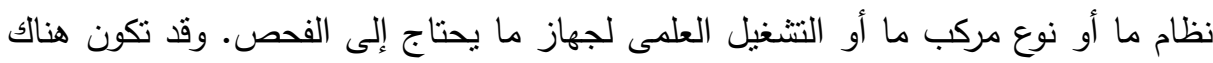
قابلية للنعرض للخطر إذا كان سبب خطر ما يرجع إلى لنوع محدد من أنواع الحوادث.

\section{تحليل نتائج الحوادث}

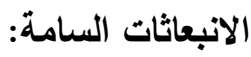

• تم عمل نموذج للانبعاثات السامة وتم استخدامها. ويسمح النموذج الرياضى بعمل نماذج

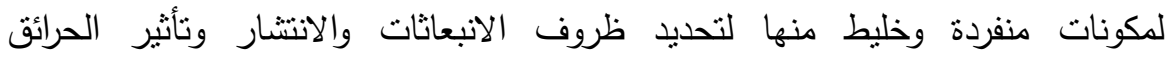
والانفجارات بناء على ظروف العملية المبئية.(د.طارق عيد محمد ، إدارة المخاطر

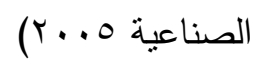

• م عمل نماذج لجميع المنسربات على فرض ارتفاع الانبعاثات إلى ب م من الغاز المكتف منل الكلور وباستخدام الظروف الجوية المفترضة لأغراض عملية تقييم النتائج. وتم عمل نماذج لانبعاثات الغاز بافتراض وجود إنبعاثات أفقية وافتراض إنبعاثات سائلة 
متجهة إلى أسفل وبهذا ينتج عنها أقل قوة دفع مدكنة وأسوأ حالات الانتشار على مسافات.

• تم أخذ البيانات الخاصة بالأحوال الجوية من الثركة تم عمل نماذج للنتائج على افتراض وجود حالات جوية سيئة (من وجهة نظر مسافات المخاطر المقدرة). ولم تكن نتائج

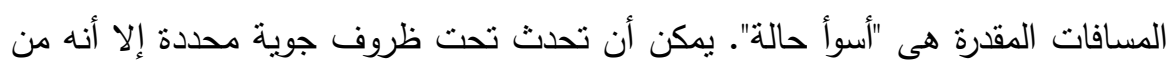
المتوقع أن يتحفظ عليها فى أغلب الظروف الأخرى. وعلى هذا ، استخدمت أقل درجة التهن

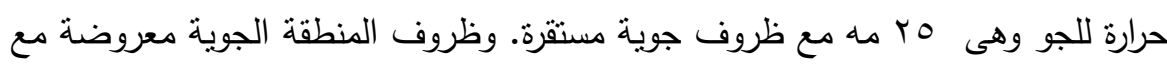
بيانات حالة الرياح المحلية.

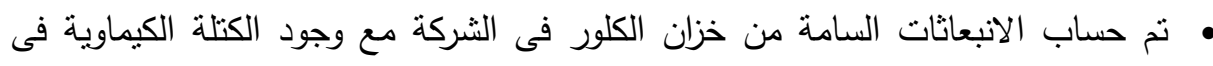

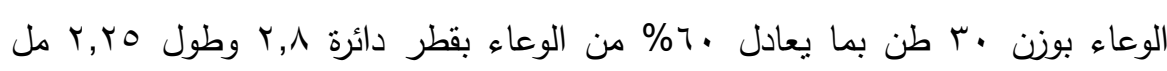

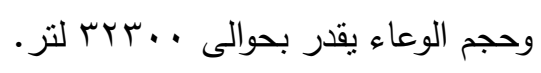

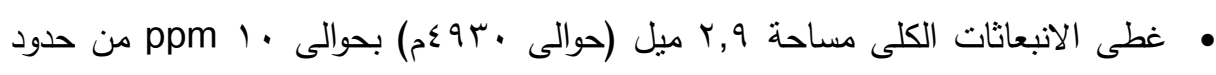

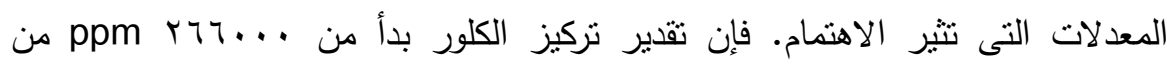

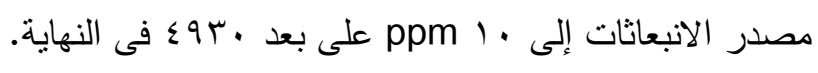

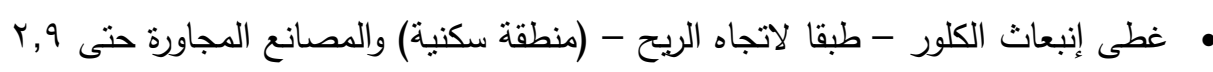

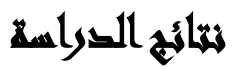

• إن خطة الاستجابة للطوارى، فى حالة وجودها ليست كافية أو كفؤ لمواجهة الحادثة ونتائجها.

• ل ل يوجد نظام منكامل فى المنشآت الصناعية لحالات الطوارىء ومواجهتها.

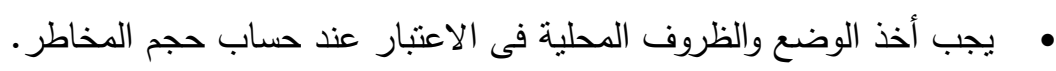

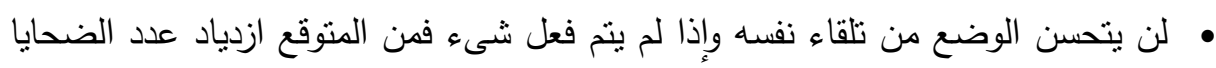

$$
\text { والحوادث الخطرة. }
$$

• إن تسرب الغازات السامة والحرائق والمواد المتفجرة ليست استثائية لأنها تحدث بإستمرار • 
• لم تتخذ إجراءات السلامة بصورة كاملة فى المنشآت الصناعية لحماية العمال والسكان

والبيئة.

• قد يكون لنسرب الغازات السامة نتائجه على السكان بالإضافة إلى أعداد الضحايا الناتج

• معظم العمال ليس لديهم التوعية الكافية بالمخاطر الممكنة للمواد الخطرة. كما أن معدات

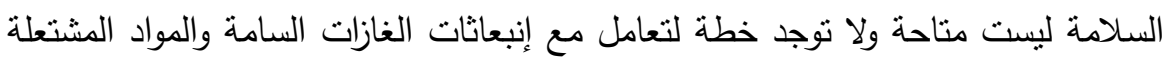

والمتفجرة.

• كثفت هذه الدراسة عن ضعف آداء المديرين فى الجهات المحلية المسئولة على مختلف ولفئ

مستوياتها.

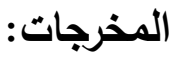

• تقوم هذه الدراسة بتطبيق عملية اتخاذ القرار الذى يينى على ادارة المخاطر مرورا بتقييم

المخاطر للتحكم فى المواد الخطرة المستخدمة فى الصناعة بمصر مبنية على البيانات

العلمية الصحيحة وتأخذ فى اعنبارها المعلومات الخاصة بمعدلات الخطر المناسبة

ومعلومات الاستخدام والتعرض فى نموذج لتقيييم المخاطر مع أمكانية التتفيذ .

• تقوم الدراسة بتوفير المعلومات الخاصة بتحديد الأولويات وتصنيف المخاطر وإداراتها فيما يتعلق بالاستخدام الآمن للكيماويات.

• يجب أن تنبى هذه المعلومات على منهاج إدارة علمى مبنى على إدارة المخاطر ، وبالنسبة

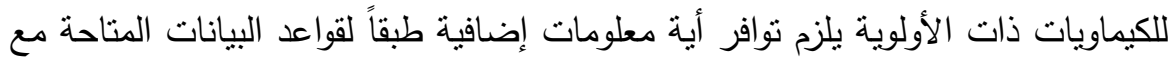

$$
\text { تقييم الإطار العام لها. }
$$

• ضرورة توفير المعلومات المناسبة والخاصة بالتأثير على البيئة للمنشآت الصناعية في

$$
\text { ووضعها فى النطاق العام. }
$$

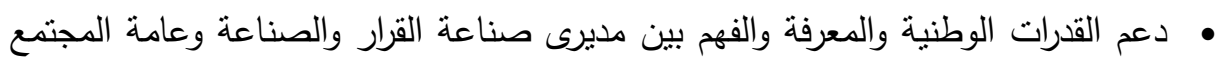

فيما يتعلق بالمواد الخطرة. 
• إصدار خطوط إرشادية لرفع معدل السلامة وحماية صحة الإنسان داخل المنشأة الصناعية.

• تعميم إجراء تحليل للمخاطر فى المناطق الصناعية الأخرى والصناعات المنوسطة والصغيرة فى مصر •

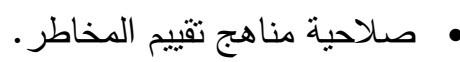
• تقديم ومناقتشة استراتيجية تقييم المخاطر مع الجهات المسؤلية (جهاز شئون البيئة) وممنلو قطاع الصناعة. • • تبنى العمل بإجراء رسمى لتقييم المخاطر تكون المخرجات أساس له. • إصدار الوثائق الفنية التى تلخص لإهى المعلومات الخاصة بالالزام القانونى بالاتفاقية الدولية

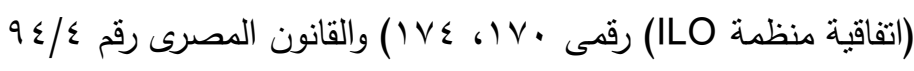
• التقييم العميق لعملية تحليل المخاطر ينتج عنها التعاون مع الثركات المعنية. • • تبنى العمل بالمنهاج طبقاً لما ورد فى هذه الدراسة وتوصياتها.

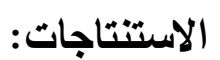

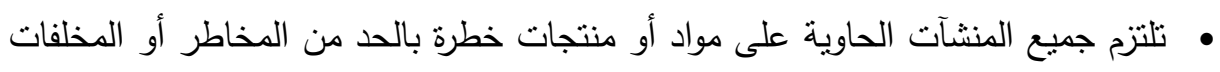
الخطرة إلى المعدل الذى تسمح به السلطات المسئولة. • يج فحص وتحديث جميع إجراءات السلامة فى أغلبية المنشآت بصورة جيدة.

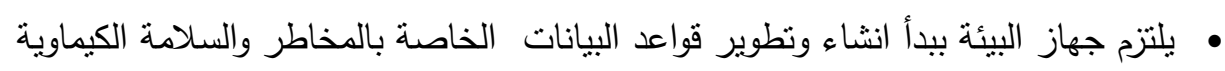

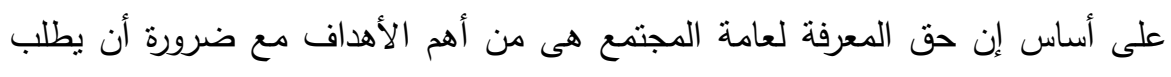
جهاز البيئة دراسات المخاطر للمنشآت الجديدة. 


\section{توكياهت التوراسة}

يتشارك الجهات المعنية والمشاركة فى الخطة الوطنية للكوارث والأزمات ومنتجو

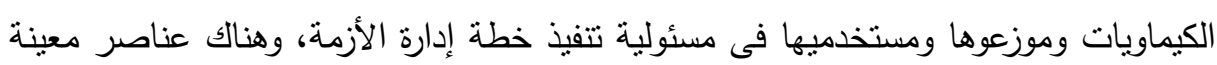

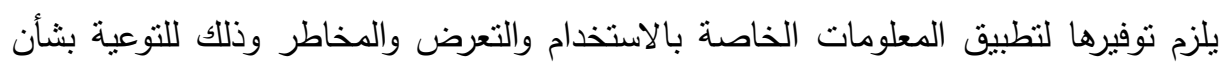

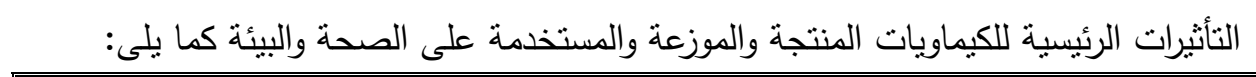

\begin{tabular}{|c|c|c|c|c|c|}
\hline الزمني & المسئول & أدوات التطبيق & النتائج & التوصية & P \\
\hline سنة & - وزارة - وزارة الإيئة & 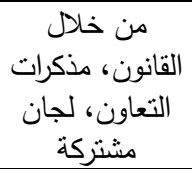 & 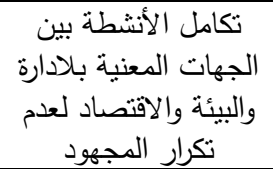 & البيئي من مالنادلة الاتزانئ الإدارة & 1 \\
\hline أثشر & لجنة الكوارث & خطة الكوارث & اللوصول بها من كارثارثة البيئة & خطة الكوارث البيئية. & $r$ \\
\hline سنة & - - وزارة الصناعة - وليئة & - & دعما للإفتتصاد على المواد الحد & تعظيم الإستفادة من الكنيماد المنيادية & $\mu$ \\
\hline سنة & - وزارة الصناعة - وزارة & - & - حماية البيئة والأثار - تحدة الأضرار - & 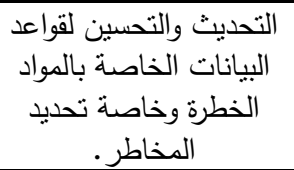 & $\varepsilon$ \\
\hline سنة & - وزارة الصناعة - وزارة & - & 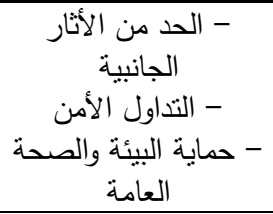 & 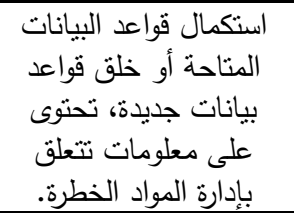 & 。 \\
\hline
\end{tabular}




\begin{tabular}{|c|c|c|c|c|c|}
\hline الزمني & المسئول & أدوات التطبيث & النتائج & التوصية & م \\
\hline سنة & - البيئة - وزارة & - - قرارات وزارية & 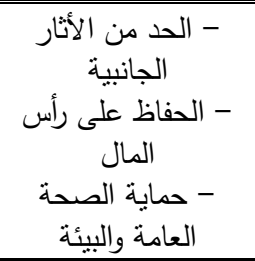 & 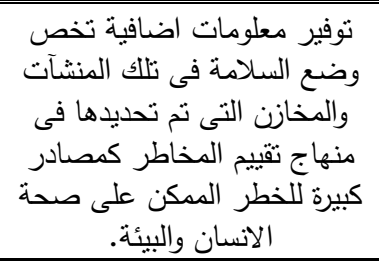 & 7 \\
\hline سنة & - البيئة - وزارة & 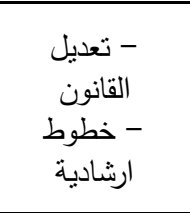 & 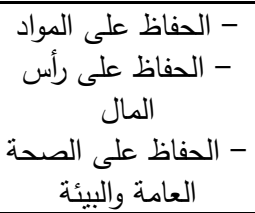 & 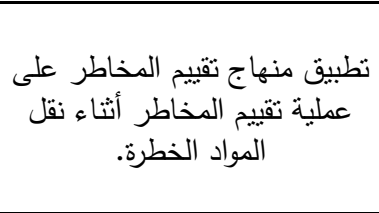 & v \\
\hline سنتان & - البيئة - وزارة & 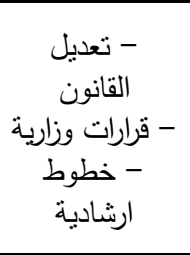 & 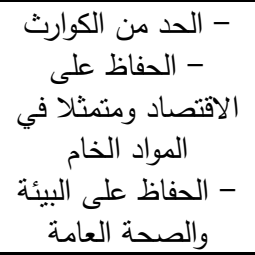 & 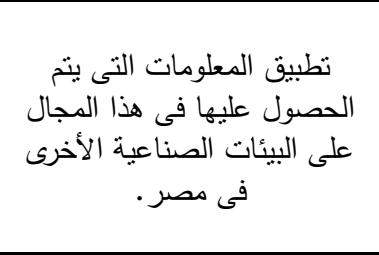 & $\wedge$ \\
\hline سنتان & الكوارثة الجنة & - ل الوطنة الكوارث - & 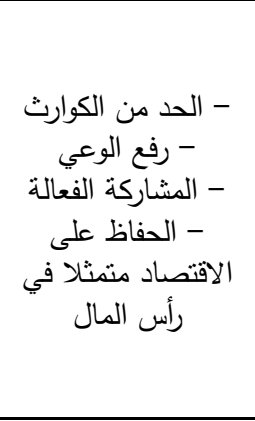 & 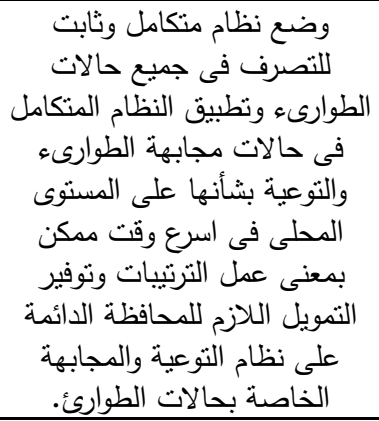 & 9 \\
\hline سنتان & الكوارث - لجنة & - - قرارات وزارية & 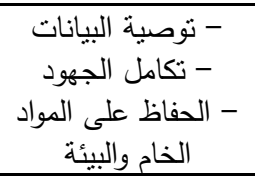 & 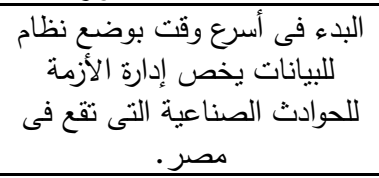 & 1. \\
\hline سنة & الكوارث - لجنة & - قرارات وزارية - & 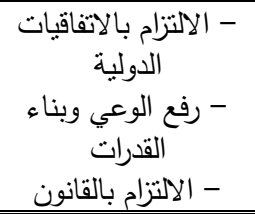 & 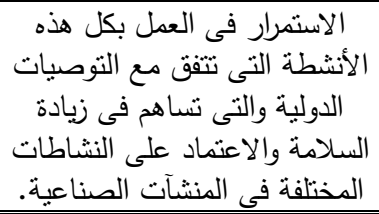 & 11 \\
\hline
\end{tabular}




\begin{tabular}{|c|c|c|c|c|c|}
\hline الزمنى & المسئول & ألتطبيت & النتائسج & التوصية & م \\
\hline سأشهر & الكوارثة - لجنة & - & 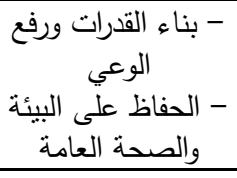 & 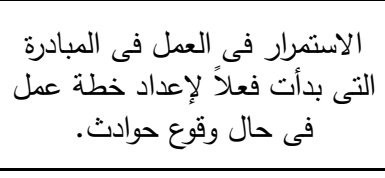 & ir \\
\hline سنتان & $\begin{array}{l}\text { - وزارة البيئة - وزارة } \\
\text { - الكناعة - لجنة } \\
\text { - الكوارث }\end{array}$ & - & - الحديد مواقع - الاستعداد الجيد - الحند - & تطوير المنظور الوطنى للمخاطر & ir \\
\hline سنة & 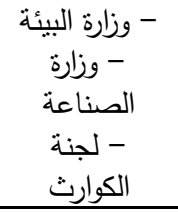 & - & - - الحديد مواقع - الاستعداد الجدة من الأثار - & 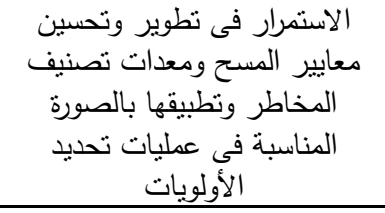 & $1 \leq$ \\
\hline سنة & 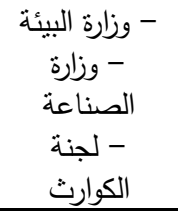 & - & - - الحديد مواقع - الاستعداد الجيد من الأثار - & 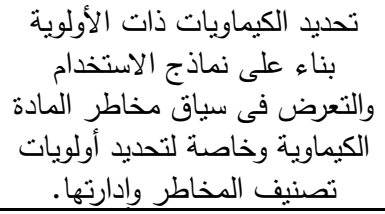 & 10 \\
\hline سنة & 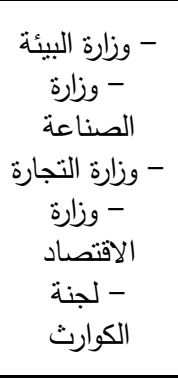 & - & 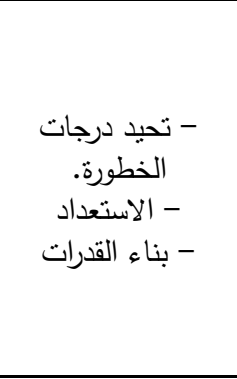 & 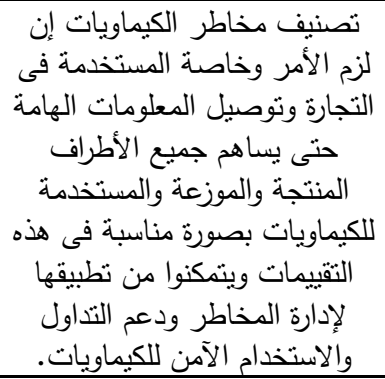 & 17 \\
\hline سنتان & 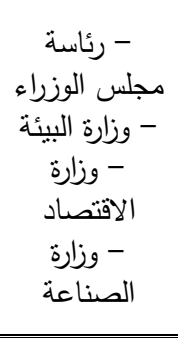 & 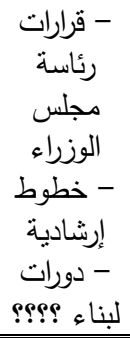 & - - وضع المواصفايد المعاير & 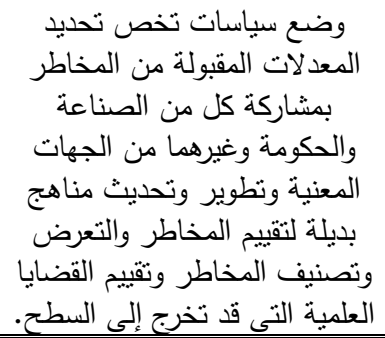 & iv \\
\hline
\end{tabular}

المجلد السادس والأربعون، الجزء الثالث، يونيو 9 ـ ب 
شريف الطنطاوى محمد فريد وآخرون

\begin{tabular}{|c|c|c|c|c|c|}
\hline الزمني & المسئول & أدوات التطبيق & النتائج & التوصية & م \\
\hline سنة & الكوارث - لجنة - وزارة & - خطوط - خرارات وزارية & - الحديد مواقع - الاستعدرة & 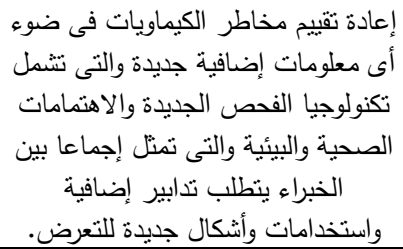 & 11 \\
\hline أشهر & 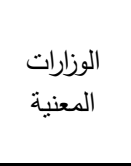 & - & 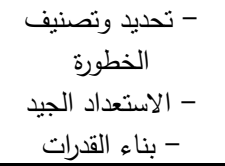 & 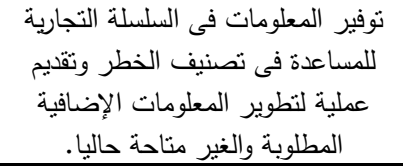 & 19 \\
\hline أشهر & - البيئة - وزارة & - قرارات وزارية & 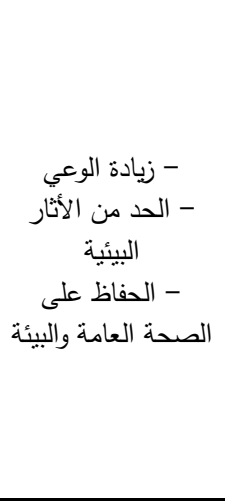 & 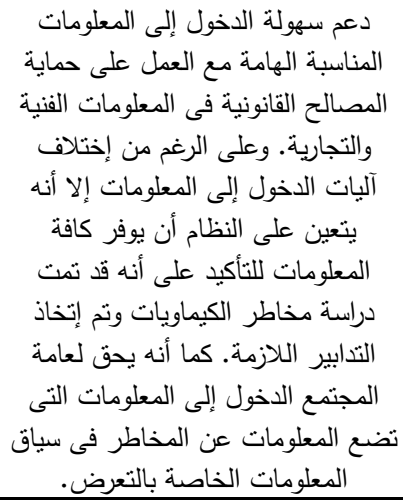 & $r$. \\
\hline سنتان & بالتشارجية & الوزارار - المية مع وزارة & - ت الخديد وتصنيف - تورية المفاهيم - & 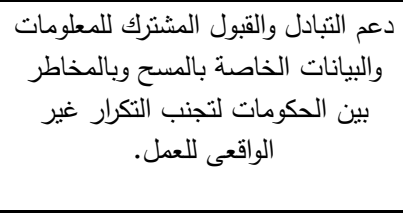 & r \\
\hline سنتان & الكال المنية المنارث & - - خرارات وزارية - دورات تدريبية - & 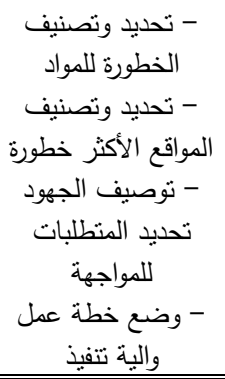 & تطوير استراتيجية وطنية للحد من & rr \\
\hline
\end{tabular}




\section{المرالم}

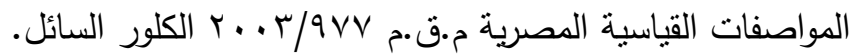

طارق عيد محمد محمود: جهاز شئون البيئة، الخطوط الارشادية لبادية للتعامل الأمن مع الكلور،

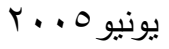

طارق عيد محمد: جهاز شئون البيئة، الاشتراطات والمعايير اللازمة لتداول وتخزين المواد الخطرة تخزينا أمنا

Bilo $M$ and Kinsman P.(1997): MISHAP-HSE's pipeline risk assessment methodology. Pipes and Pipeline international. July - August.

Carruthers, N., (1987): Development of societal Risk Criteria for Australia, M.Eng Thesis, university of Sydney.

DNV Technica, (1992): Risk Assessment Training Course, For department of Transport, Project c3386.

Femandes Russell, D.P., (1987): Societal Risk Estimates from Historical Data for UK and Worldwide Events, school of Environmental Science, University of east Anglia.

Groningen Province, Ca. (1979): Pollution Control and use of Norms in Groningen, Unpublished document.

Henderson, N. (1987): Living with Risk: The British Medical Association Guide, Wiley \& Sons, London.

Van den B erg (1985): The multi energy method. A framework for vapour c loud explosion blast prediction. Jnl Haz Matis 12, 1-10.

HSC, (1991): Major Hazard Aspects of the Transport of Dangerous Substances, Health \& Safety Commission, Advisory Committee on Dangerous Substances, HMSO, London.

HSE, (1978): Convey - An Investigation of Potential Hazards from Operations in the Convey Island/Thurrock Area, Health \& Safety Executive, HMSO, London.

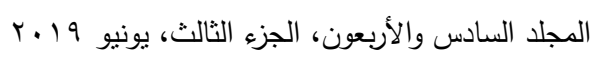


شريف الطنطاوى محمد فريد وآخرون

\title{
A PROPOSED FRAMEWORK FOR \\ ENVIRONMENTAL CRISIS MANAGEMENT IN \\ INDUSTRIAL DISASTERS \\ AN EMPIRICAL STUDY ON ONE OF THE INDUSTRIAL ZONE FACTORIES (TENTH OF RAMADAN)
}

\author{
Sherif A. M. Farid ${ }^{(1)}$; Nehal M. F. El- Shahat ${ }^{(1)}$ \\ and Tarek E. M. El-Robby ${ }^{(2)}$
}

1) Post Grad. Institute of Environmental Studies\&Research, Ain Shams University 2) Academy for Science, Technology \& Marine Transportation

\begin{abstract}
In this study, the issue of decision-making, which is based on the management of the environmental crisis, is addressed by balancing the balance through the economic and environmental aspects and risk assessment to control the dangers of hazardous materials used in industry in Egypt, to maximize the use of resources in support of the Egyptian economy.

The crisis management process is based on risk management, whether natural or man-made and focuses on protecting public health and the environment and reducing economic losses due to the disastrous consequences of disasters, including major accidents, which can occur during the industrial processes of handling, manufacturing and storing hazardous materials.
\end{abstract}

